\title{
كلود كاهن
}

\section{Claude Cahen}

$$
(\text { p) 991-19.9) }
$$

أ.د. محمة مؤنس عوض العتر

أستاذ تاريخ العصور الوسطي

كلية الآداب - جامعة الثارقة 

الملخص:

يعد المؤرخ الفرنسى البارز كلود كاهن رائدًا فى دراسة تاريخ الحروب الصليبية؛ حيث أصدر عدة دراسات تتاولت العلاقات بين الشرق والغرب خلال تلك الحقبة. هذا البحث يسلط الضوء على رؤية للحرب العالمية فى العصور الوسطى وأعني بها الحروب الصليبية. 


\section{Abstract:}

Claude Cahen, the Outstanding French historian, has a leading role in the Studying of the crusades. He published several studies dealing with the relations between east and West during that vital epoch.

This paper focuses on Claude Cahen Viton towards the universal war in the Middle Ages which is mean the crusades. 


\section{كلود كاهن}

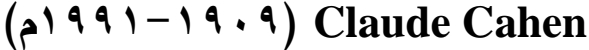

يتاول البحث بالدراسة تعريفًا بالمؤرخ الفرنسي الرائد والبارز كلود كاهن

$$
\text { ورؤيته لصلاح الدين الأيوبي. }
$$

ولد المستشرق اليهودي الفرنسي المذكور في 7 فبراير 9.9 ام، قبل اندلاع

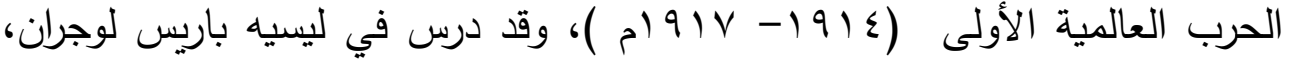
ومن بعد ذلك التحق بمدرسة المعلمين العليا، وبالمدرسة الوطنية للغات الثرقية الحية،

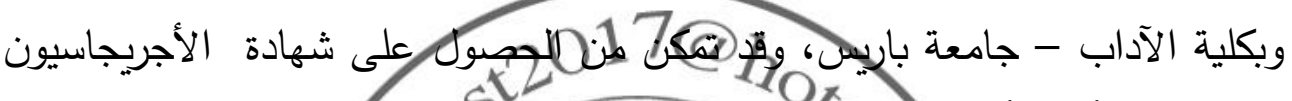

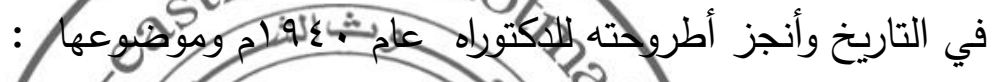

La Syrie du norday'époque des Croisade ét.la principauté Franque d'Antioche

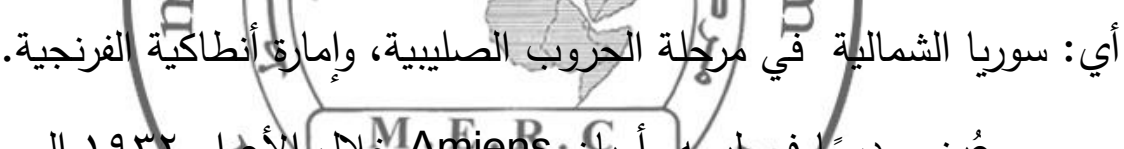

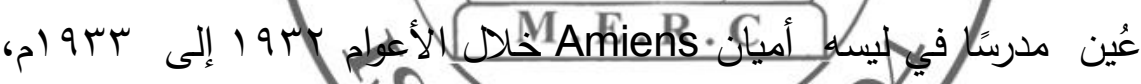

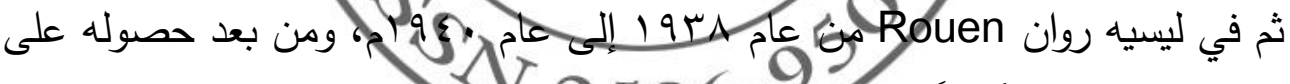

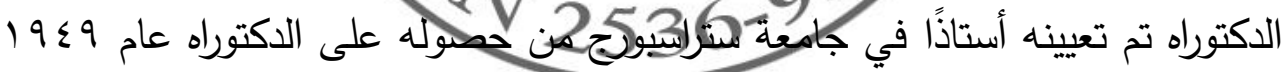
إلى عام 909 (م، ثم صار أستاذًا في السوربون من عام 909 إلى عام 9 (م ('). تولي كلود كاهن رئاسة تحرير مجلة : Journal of Economic and Social History of Orient. أي مجلة التاريخ الاجتماعي والاقتصادي للمشرق، كذلك صار رئيسًا للجمعية

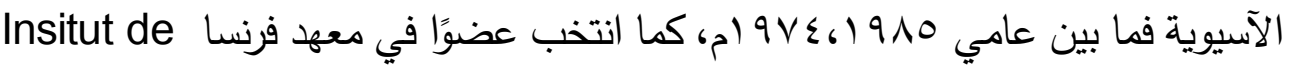
France 
أجاد المستشرق البارز المذكور عدة لغات كاللاتينية، والعربية، والفرنسية، والإنجليزية، والإيطالية، والألمانية على نحو انعكس على مؤلفاته العلمية القيمة. اتجه إلى الانضمام إلى الحزب الشيوعي الفرنسي فيما بين عامي • ب9 إإلى • 97 (م، وعلى لإلى الرغم من يهوديته إلا إنه لم يدعم الكيان الصهيوني في فلسطين، وأشرف على العديد من الطلاب العرب مثل أ. د أحمد عبد الرازق وأ. د. صدلاح بحيري وغيرهما.

توفى المستشرق المذكور في يوم 1) نوفمبر (99ام عن عمر بلغ عامًا، وكان قد فقد بصره من كثرة مطالعة المخطوطات العربية التي عشقها. أصدر كلود كاهن العيد من الإصدارات نذكر منها: عن مؤلفات كلود كاهن انظر :

1- Islam, Paris 1971.1,eroque

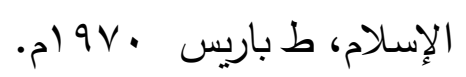

2- La Syrie du nord a le poque des Croisades et La principauté Franque d'Antioche, Paris 1940.

سورية الثمالية في مرحلة الحروب الصليبية وإمارة انطاكية الفرنجية، باريس • ع 19 3- Orient et Occident au Temps des Croisades, Paris 1983.

$$
\text { الثرق والغرب في زمن الحروب الصليبية،ط. باريس به9 ام. }
$$

4- Les Peuples Musulmans dans 1, histoire médiévale Damans 1977.

$$
\text { الشعوب الإسلامية في التاريخ الوسيط.دمشق 9VV ام. }
$$

5-Turco -byzantine et Orient Chrétien ,London, Variorum reprint 1974.

$$
\text { الترك والبيزنطيين والثرق المسيحي، لندن، فاريورم،ط. ع \9 ام. }
$$


6- Claude Cahen ,"La Campagne de Mantzikert d'après Les musulman "B.IX,1934 ,PP.613- 642.

كلود كاهن، معركة مانزكرت من خلال المصادر الإسلامية، مجلة بيزانتيون، العدد

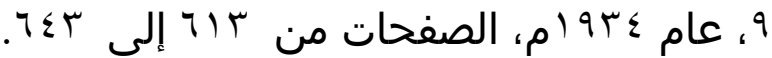

7-"Le Diyer Bakr au Temps des premiers urtukides ",J.A.CCXX II,1933,PP.219-279.

ديار بكر في زمن الأراتقة الأوائل، الجريدة الأسيوية، العدد VYr، عام Oب9 19،

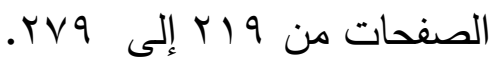

8- " La première infiltration turque en Asie Mineure", la seconde moitié de l'athée siècle, $\mathrm{n}^{\circ}$ 18, 1948, pp 5-67.

التسلل التركي الأول في آسيا الصغرى، النصف الثاني من القرن الحادي عشر، العدد

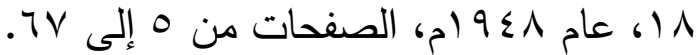

9-" Notes sur 1, histoire des croisades et d'Orient latin: 1.En quoi la Conquête Turque appellera -t- La croisade ?" B.F.L.U.S.XX IX,19501951,PP.118-125.

مذكرات على الحروب والثرق اللاتيني : ا- إلى أي مدى أدي الغزو التركي إلى

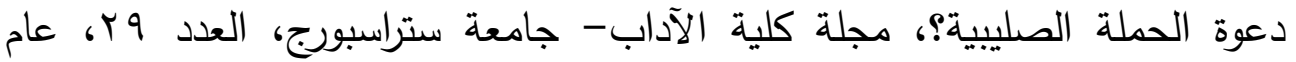
(909 1م، الصفحات 111

10-" Notes sur 1, histoire des croisade et d'Orient latin: 2-le régime rural Syrien au Temps de la domination Franque" ,B.F.L.U.S,XXXIX, 1950-1951 , pp 282-310. 
مذكرات على الحروب الصليبية والشرق اللاتيني :r الريف السوري في زمن السيادة

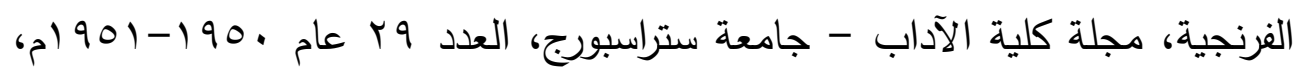

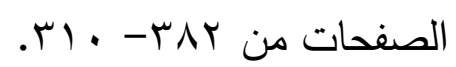

11- Notes sur 1, histoire des croisade et d'Orient latin :3- Orient latin et Commerce du Levent,B.F.L.U.S,XXXIX,1950-1951.;328- 346.

مذكرات على الحروب الصليبية والشرق اللاتيني : :- الشرق اللاتيني وتجارة شرق البحر المتوسط "، مجلة كلية الآداب - جامعة ستراسبورج العدد 9ب عام • 190 -

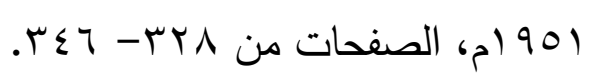

12- "Commerce anatolien et début du XIIIe siècle," in Mélanges de Histoire du Moyen Age, dédies a la mémoire de Louis Halphen ed Charles E. Perrin, Paris 1951, pp. 91-101.

" التجارة الأناضولية عند مطلع القرن الثالث عشر الميلادي " في الكتاب التذكاري لتاريخ العصر الوسيط، مقدم لذكرى لويس هالفن، نشر شارلز أي بيرين،ط. باريس

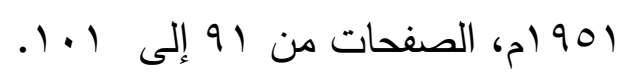

13-" Pour l'histoire des Turcomanes d, Asie Mineure au XIIIe siècle, la Gazette asiatique No. 339 en 1951, pp 325-354.

من أجل تاريخ التركمان في آسيا الصغرى في القرن الثالث عشر الميلادي، الجريدة

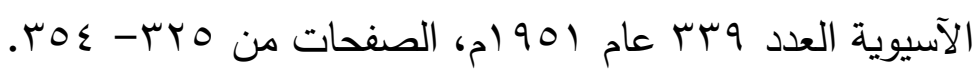

14- L'évolution de L,iqtaa du IXème au XIII eme siècle d,un Histoire Comparée des sociétés médiévales Annales: économiques sociétés Civilisations 1953,PP.25-52. 
تطور الإقطاع في القرن التاسع حتى القرن الثالث عشر الميلادي: دراسة التاريخ المقارن لمجتمعات العصور الوسطى الحوليات الاقتصادية والاجتماعية والحضارية، عام س 90 1، والصفحات من Or إلى

15- "Notes sur les de butes de La Futuwwa d,au de Nasser O.VI,1953,PP18-22.

مذكرات من بداية فتوة الناصر ، مجلة أورينز ، العدد السادس، عام 90 (، الصفحات من 11 إلى

16- Introduction to the first Crusade, , p.p., 1954,No6,pp.6 - 29.

مدخل إلى الحملة الصليبية الأولى، مجلة الماضي والحاضر،ط. عام 90 (م،مجا

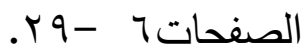

17- "1,Islam et la croisade, les Relazioni del congres su internationale di cienze STO riche ,Rome1953:3 Soria del moyen evo Florence 1955, pp.625 à 635 .

"الإسلام والحروب الصليبية"، أعمال المؤتمر الدولي العاشر لعلم تاريخ روما 900 ام،

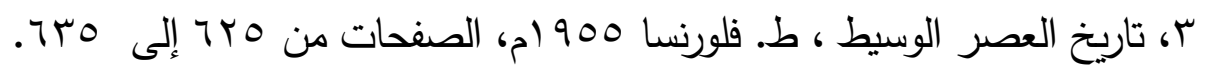
18- " La de Féodalité et les Institutions politiques de l'Orient latin et Occidentale medio Ero, Rome 1957,pp. 167 à 191

الإقطاع والنظم السياسية للشرق اللاتيني، في الثرق والغرب في العصر الوسيط 190V

19- Le première cycle de le croisades, M.A.,LVII,1957,pp 612-328. 
القرن الأول من الحروب الصليبية، مجلة العصر الوسيط العدد ب7،عام 90 (م،

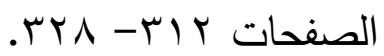

20-"Les mouvements populaires et l'indépendance urbaine en Asie musulmane au Moyen-Age", Arabica, n ${ }^{\circ} 5$ 1958,. PP.225-250 ,1959, Et 233-250

الحركات الشعبية والاستقلال الحضري في آسيا المسلمة في العصر الوسيط، أرابيكا،

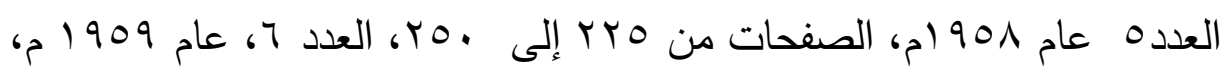

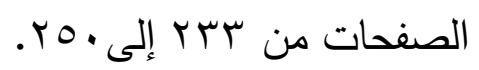

21- douanes et du commerce dans les ports la Méditerranée de égypt. Médiévale d, près le Minhadj d, al Makhzoumi, J.E. S.H.O.,VII ,1964,PP.217 à 314.

الجمارك والتجارة في الموانئ المصرية المطلة على البحر المتوسط في العصر الوسيط من خلال كتاب المنهاج للمخزومي، مجلة التاريخ الاقتصادي والاجتماعي

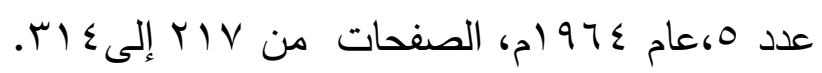

22- pré- ottoman Turkey: a general of survey of Material spiritual culture 1071- à 1314.Tr.J.J. Jones - William, New York 1968.

تركيا ما قبل العثمانيين مسح عام للثقافة المادية والروحية من عام اV• (1- ‘إلى

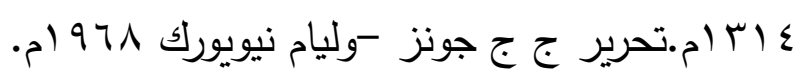

23- La politique Orientale des Comtes des Flandre et la Lettre Alexis Comnence, mélanges de islamologue Volume dédie a la mémoire de Armand Abel ed. Pierre, Salmon i. Leyden 1971, pp. 84 à 90. 
السياسة الثرقية لكونتات الفلاندر وخطاب الكسيوس كومنين، الكتاب التككاري

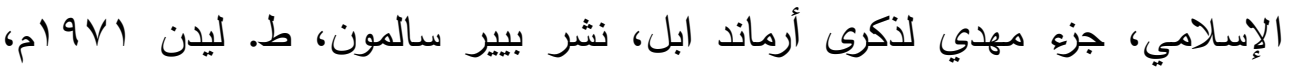
الصفحات من ع 1 إلى .9.9.

24- Turco Byzantins et l'Orient chrétien, i. Londres 1974.

$$
\text { الترك البيزنطيون والشرق المسيحي،ط. لوندرز ع ام. }
$$

25- Amalfi en Orient a Ville, au moment et au Lendemain de la Première Croisade", in Amalfi mèl medio evo, ,Salerno 1977, pp. 84 à 90.

أمالفي في الثرق تاريخ حاضرة في وقت الحملة الصليبية الأولى وفيما بعد ما، ضمن

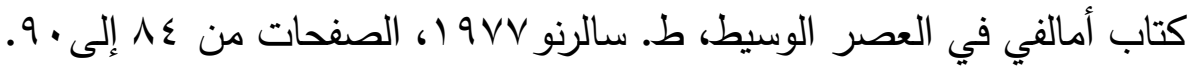
26- Le commerce Amalfi dans le Proche-Orient Musulman avant et après la première croisade C.R.I.B.L., 1977, pp. 291 à 300.

تجارة أمالفي في الشرق الأدنى الإسلامي فيما قبل وبعد الحرب الصليبية الأولى ضمن كتاب التقرير العالمي لأكاديمية النقوش والآداب، عام 9VV (م، الصفحات من

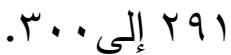
من أهم مؤلفات كلود كاهن في مجال الحروب الصليبية، كتابه: أي الشرق والغرب في عصر الحروب الصليبية، باريس rم9 ام.

Orient et Occident au Temps des croisades ,paris 1983.

أعتمد في دراستي عن رؤيته لصلاح الدين الأيوبي وإنجازات المسلمين تحت قيادته عند دراستتا لرؤية المؤلف الفرنسي البارز كلود كاهن لصلاح الدين الأيوبي، نلاحظ أنه خصص عنه فصلًا مستقلًا (r) مما دل على أهميته المحورية في ذلك العصر . 


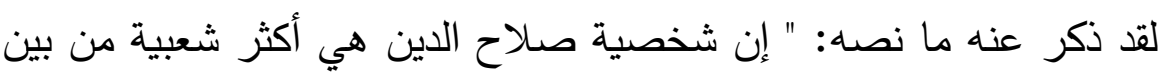

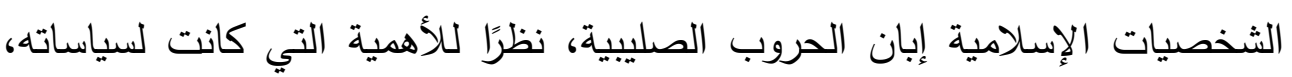

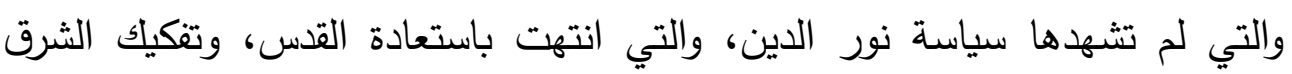

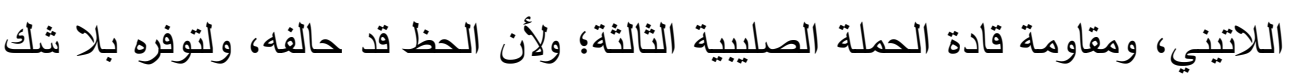

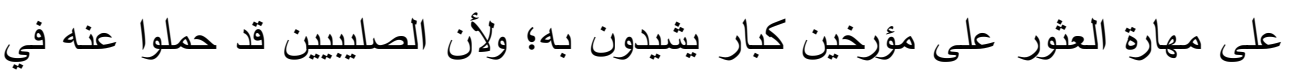

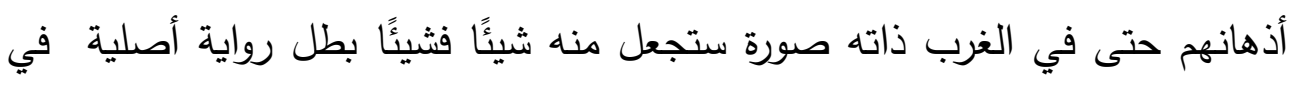

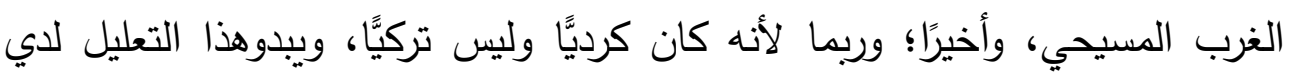

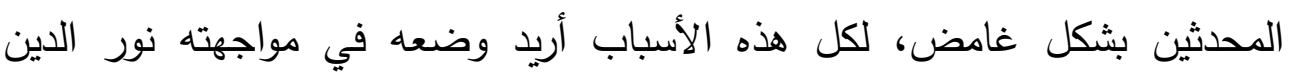

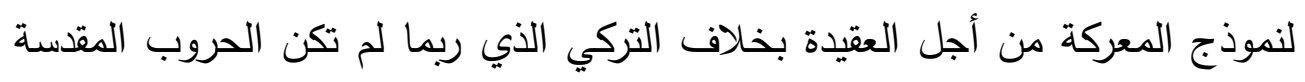
بالنسبة إليه إلا ذريعة لخدمة طموحاته "((؟). واقع الأمر من المدكن الرد على الفقرة المذكورة من خلال التالي:

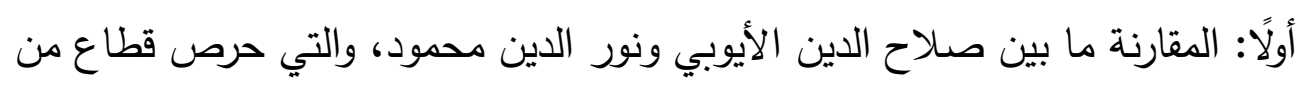

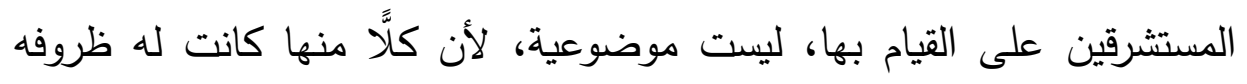

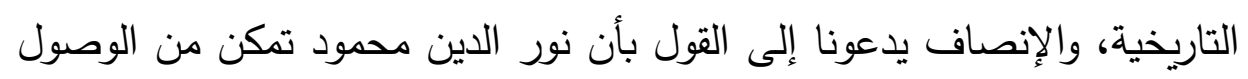

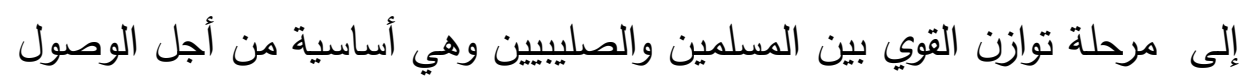

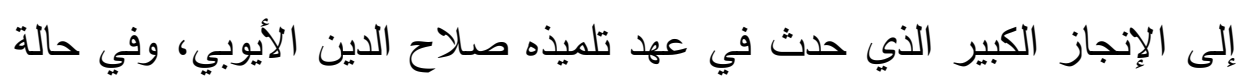

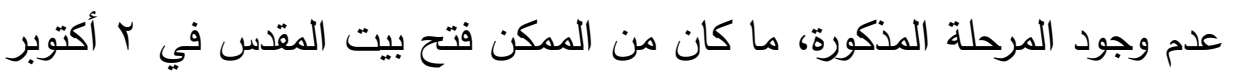
IAV

ثانيًا: جانب كلود كاهن الصواب عندما تصور فكرة "الحظ" الذي أعان صلاح الدين؛

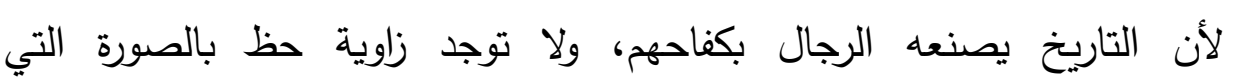

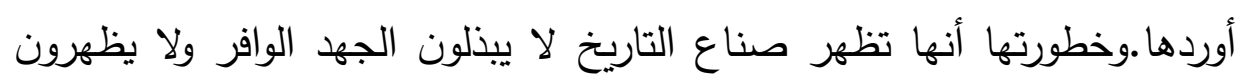

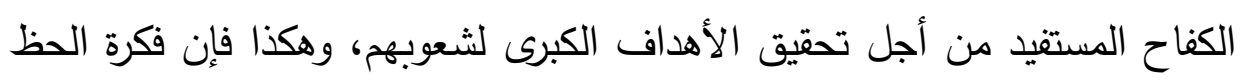
فكرة مغلوطة ولا أساس لها من واقع التاريخ. 
ثالثًا: القول أنه تمكن بمهارة من العثور على مؤرخين كبار يشيدون به، أمر مغلوط

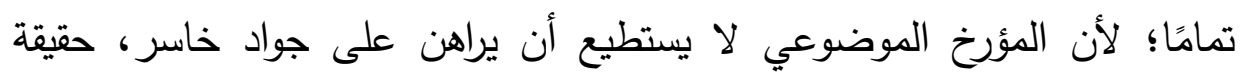

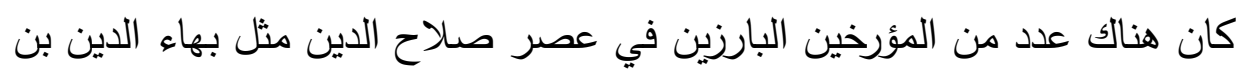

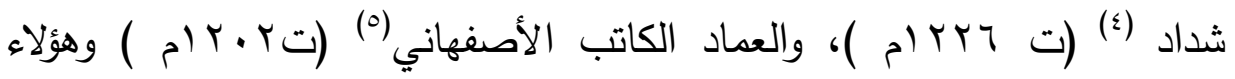

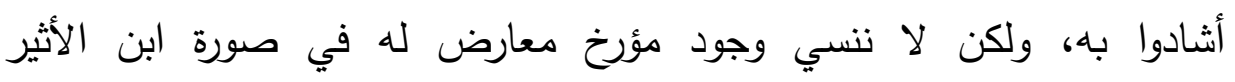

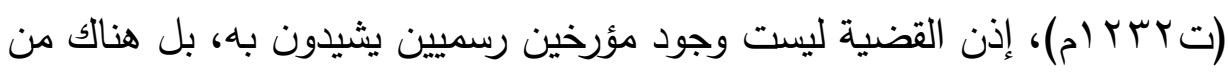

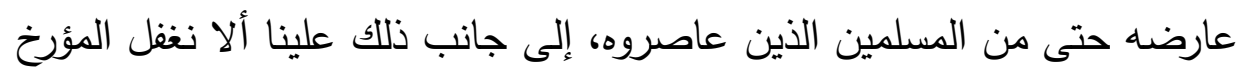

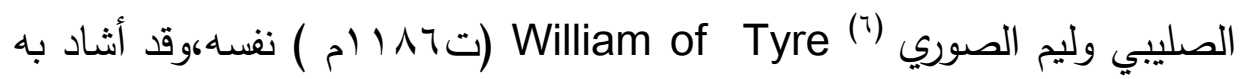
ووصفه بأوصاف إيجابية لم يقلها عن الملك عموري نفسه المعاصر له، حيث ذكر عنه أنه حكيم، ذكي، حذر، يملك روح المبادرة وكريم إلى درجة السخاء. رابعًا: حرص قطاع من المستشرقين على بذر بذور الفتنة بين عناصر المسلمين من

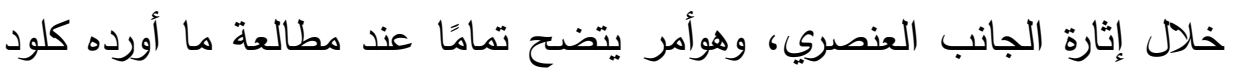

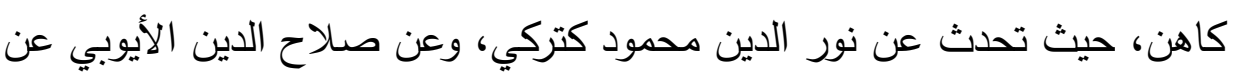
اعتبار كونه كرديًا !!؛ والواقع يؤكد أن حضارة الإسلام انصهر فيها الجميع ولا لإنا

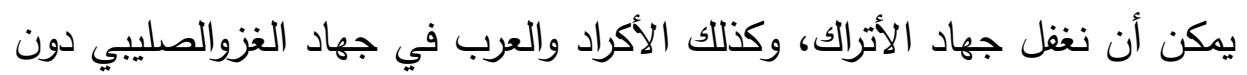
تمييز أوتفضيل عنصر على آخر؛ لأن ذلك من شأنه تفكيك الأمة، وبعثرتها وإيجاد تصارع وتناحر بين عناصرها.

خامًا: حاول كلود كاهن الإساءة إلى نور الدين محمود، وتصوره على أنه كان

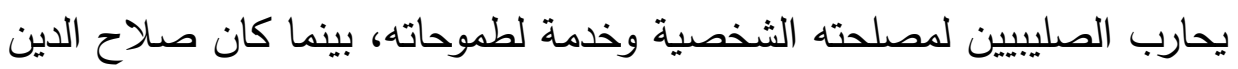

$$
\text { كان يدافع من أجل العقيدة !!. }
$$

واقع الأمر أن نور الدين محمود من أكثر المجاهدين المسلمين الذين تولوا الدفاع

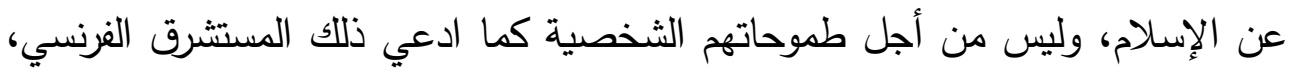


ويكفي للتدليل على الجانب الديني في شخصيته ما ذكره المؤرخ الصليبي وليم الصوري الذي وصفه بأنه أمير عادل مراع لتقاليد دينه(').وشهادة الأعداء تجب كل شل شهادة.

Nikita N من ناحية أخرى أقر المؤرخ الفرنسي البارز نيكيتا إليسيف Elisseeff نور الدين محمود، وأعد عنه أطروحته للدكتوراه (^)، أقر بأن الجانب الديني كان أساسيًّا في توجهات نور الدين محمود الجهادية ضد الصليبيين. من ناحية أخرى، أشار كلود كاهن إلى عصر صلاح الدين قد شهد تأليف مؤلفات في الجهاد، وفي فضائل المدن، وهذه حقيقة مؤكدة لها دلالتها التاريخية العميقة وكان الهحف من وراء ذللك إثارة الثعور الديني لدى المعاصرين، ومن أمثلة ذللك تأليف القاضي بهاء الدين بن شداد (ت بr (م) كتابًا في الجهاد بطلب من

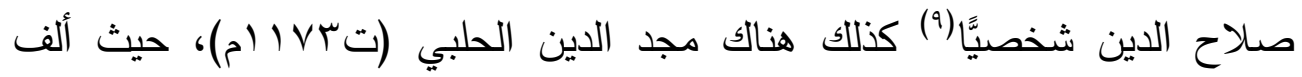

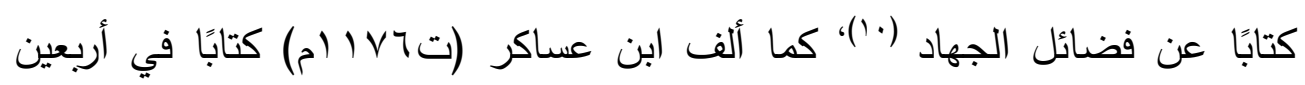
حديثًا في الحث على الجهاد ('). أما فيما يتصل بكتب الفضائل، فقد تم التأليف فيها ؛ كي يدرك المعاصرون أهمية المدن التي خضعت للاحتلال الصليبي وضرورة استعادتها لعالم الإسلام، خاصة بيت المقد، وحتى تكون الدعوة لتحريرها بها من قبضة الغزاة بمثابة قضية حياة أوموت

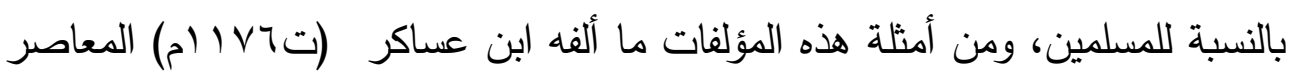
لصلاح الدين الأيوبي تحت عنوان رسالة في فضائل بيت الدقدس (rا')، ويلاحظ ان تلك الك المدينة المقدسة استأثرت بالعديد من المؤلفات في المجال المذكور . زد على ذلك أشار كلود كاهن إلى أن عصر صلاح الدين؛ ظهر فيه التأليف في مجال الأسلحة، واستشهد بذلك فيما ألفه الطرسوسي (ت 9 (1) (م) تحت عنوان "تذكرة أرباب الألباب" وهي التي حققها المستشرق الفرنسي نفسه (rا') ضمن سعيه لتحقيق مصادر

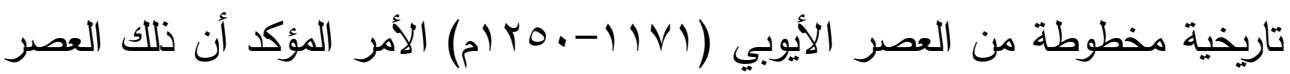


شهد اهتمامًا بالأسلحة؛ نظرًا للطبيعة الحربية للصراع الإسلامي - الصليبي، وقد حث تسابق وتتافس تسليحي بين المسلمين والصليبيين، بل وجد اتجاه لابتكار أسلحة جديدة كما لإنيلية

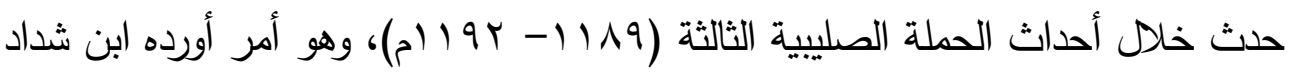
عندما تحدث عن ابتكار مادة حارقة لإحراق الأبراج التي نصبها الغزاة لإسقاط عكا.(\&)

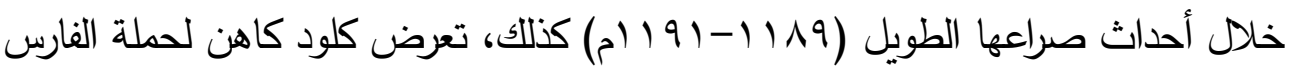
الصليبي رينودي شاتيون المعروف في المصادر العربية بأرناط التي وقعت عام سم الم، وفي ذللك قال:" في زمن صلاح الدين حدثت من الجانب الفرنجي حملة البحر الأحمر التي

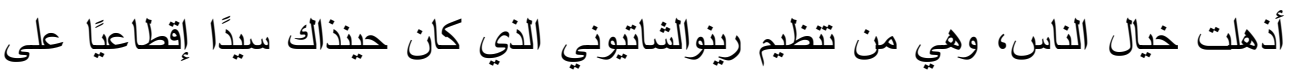
الكرك في شرق الأردن باتجاه الأماكن الإسلامية المقسة، وكان يحلوللبعض أن يرى في

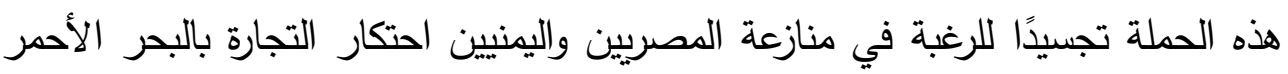
وهذا منحي جديد عن التأويل.. وإذ لا يمكن أن نتوقع من رينوالذي بدأ مسيرته في الثرق بالقيام بعملية سطوضد القبرصيين الذين لم يفعلوا له شيئًا يبرر ذللك. إلا إن يقوم بعملية نهب جديدة تكون أكثر تهورًا !!، وقد انتهت بإعدام كل المشاركين في هذه العملية، وقام

صلاح الدين بنفسه بقتل رينوحينما وقع في يده" (10) بـان

من الجلي البين أن المؤرخ الفرنسي المذكور، يقدم عرضًا دعائيًا عن رينودي شاتيون الفرنسي، ويبالغ بصورة فجة عندما يصف العملية المتعصبة الخرقاء التي قام بها، على أنها أذهلت خيال الناس، وهوأمر يخالف الواقع التاريخي؛ إذ نال ذلك الفارس المتعصب عداء وكراهية واحتقار عشرات الملايين من المسلمين في المنطقة، وتأكد للجميع أن الغزوالصليبي يعلن عن تحرير الأراضي المقدسة في فلسطين، بينما الواقع يؤكد رغبة الغزاة في ضرب الإسلام في عقر داره في الحجاز وتكوين" إمبراطورية" لهم على حساب أملاك المسلمين.

يلاحظ هنا أن نفس المؤرخ الذي وصف تلك الحملة بالوصف المشار إليه، عاد ليصفها بأنها عملية نهب جديدة تكون أكثر تهورًا، وبذلك تناقض مع نفسه في 


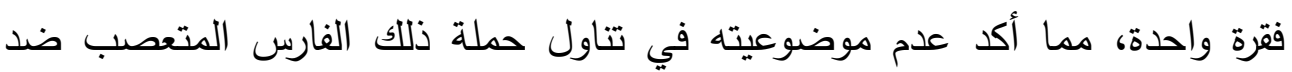

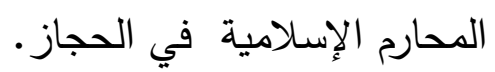

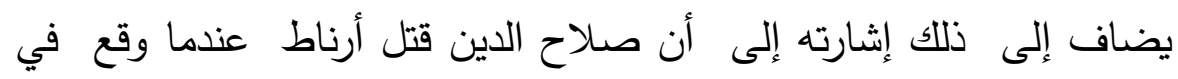

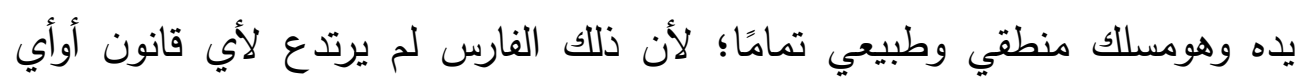

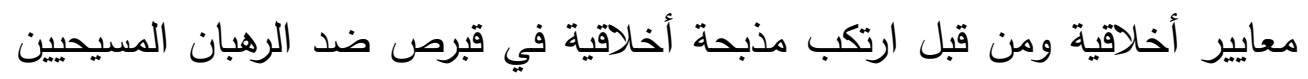

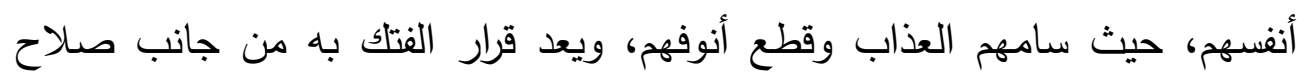

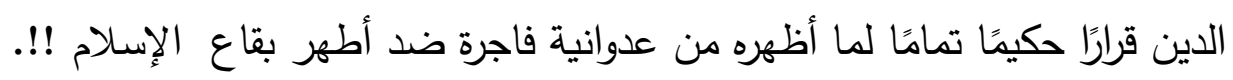

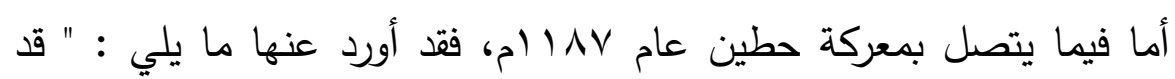

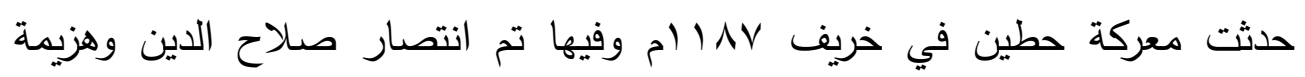

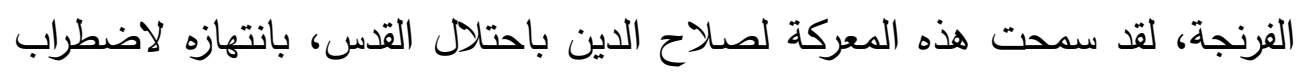

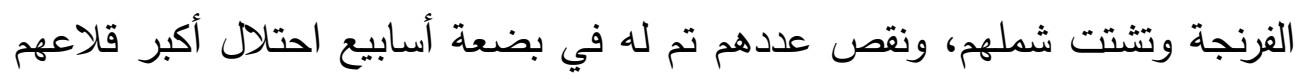

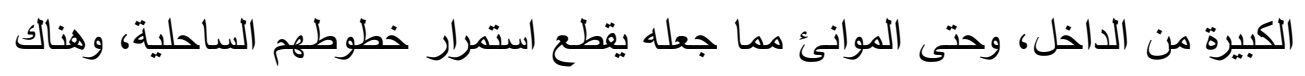

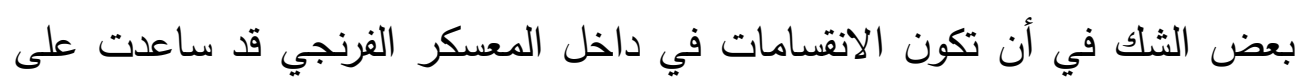
حدوث الكارثة وتعاظم نتائجها "(1').

كذلك أضاف:" يظهر تاريخ القرن اللاحق أن الفرنجة ظلوا قادين على

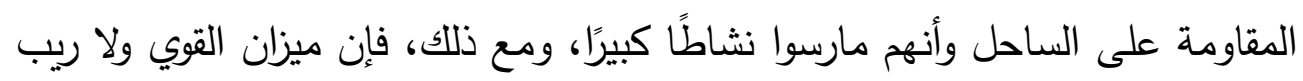

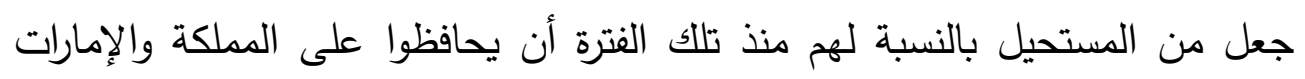

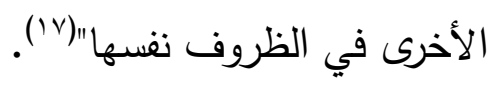

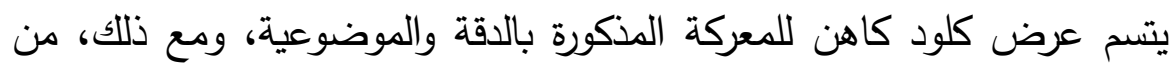

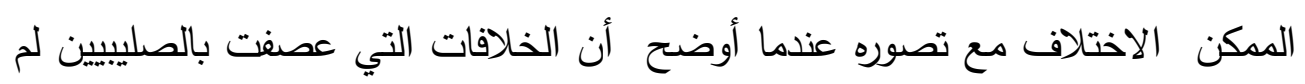

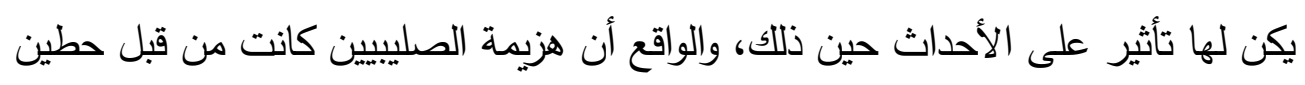

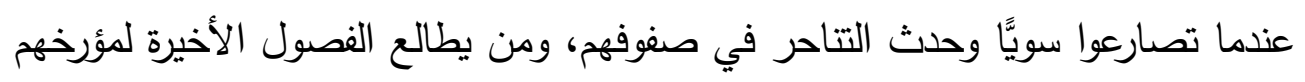

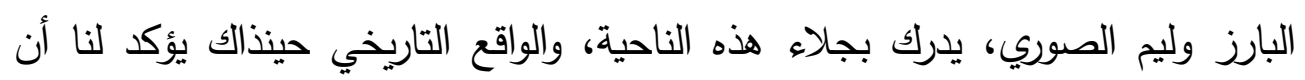


حطين وضعت حدًا لتتامي الخلافات الصليبية - الصليبية لصالح المسلمين، ولا ننسي أن السقوط دومًا في التاريخ من الداخل قبل الخارج.

من ناحية أخرى اتجه ذلك المؤرخ الفرنسي البارز الذي عرف باهتمامه بالتاريخ الاقتصادي إلى تناول سياسة صلاح الدين الأيوبي في التعاون مع المدن

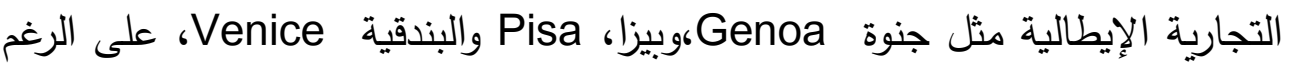
من عدائهم للمسلمين، إلا إنه أدرك عدم وجود عداءات دائمة أوصداقات دائمة في عالم السياسة، بل هنالك مصالح دائمة، وفي ذللك قال :" فيما يخص تجارة البحر المتوسط كان من المتوقع أن يضر المناخ السائد للحرب المقدسة باستمرار العلاقات التجارية مع الغرب أواستئنافها، غير أن متطلبات الحرب المقدسة ذاتها كان بوسعها أن تسير في الحقيقة في الاتجاه المعاكس، فبالنسبة لصلاح الدين كان الخشب الضروري لبناء أسطوله البحري كما كانت الحاجة إلى الحديد والأسلحة ذاتها أشد مما كان عليه الأمر مع سابقيه، ولم يكن في مقدوره أن يحصل على هذه الأمور من الإيطاليين إلا بمنحهم امتيازات كانت من الأهمية بمقدار التشديد المتزايد لهنع هذه

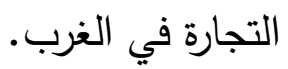

ونحن على علم بالخطاب الذي أرسله صلاح الدين إلى الخليفة، حيث يتباهى

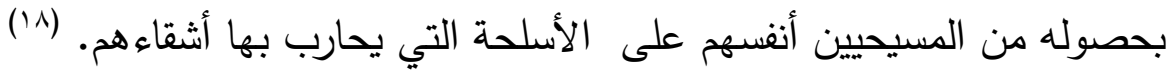
هكذا؛ كشف لنا عرض كلود كاهن عن حكمة السلطان الأيوبي الذي تعامل مع ذلك القطاع الحيوي والمهم من الصليبيين من أجل تحقيق هدفه الأسمي في تكوين جيش لهي قوي يملك القدرة على تغيير موازين القدرة في المنطقة لصالحه.

تجدر الإشارة إلى أن البنادقة - على سبيل المثال - كان شعارهم دومًا، نحن تجار أولًا ثم مسيحيون من بعد ذلك، وبالتالي كانت القضية لديهم ليست صليبية، بل مالية في المقام الأول ومثل موقفهم هذا ثغرة في وحدة الصف الصليبي عاد على المسلمين

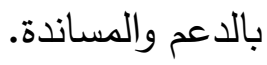


تلك أبرز إثارات المؤرخ الفرنسي كلود كاهن عن صلاح الدين الأيوبي، ومن المكن خلالها من التوصل إلى أبرز الملاحظات التالية: أولًا: اتسم عرض ذلك المؤرخ الفرنسي بوجه عام عن صلاح الدين الأيوبي بالموضوعية، إلها. وقد عرف قدره بدليل تخصيصه لفصل كامل عنه في كتابه الدذكور .

ثانيًا: كالمعتاد ردد آراء المستشرقين التي لاهدف من ورائها سوى إثارة النعرات

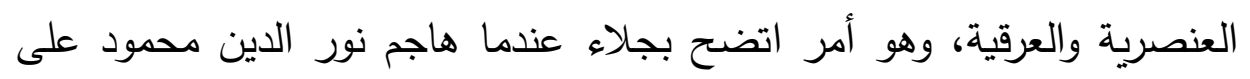

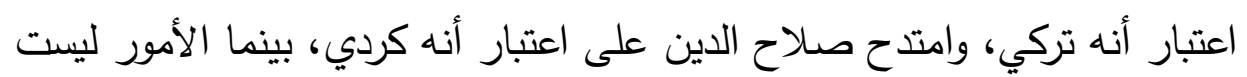

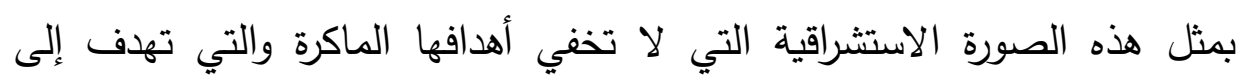

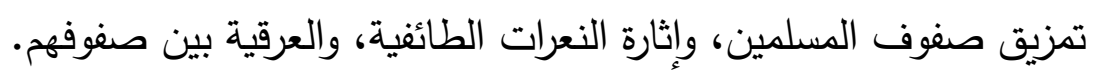

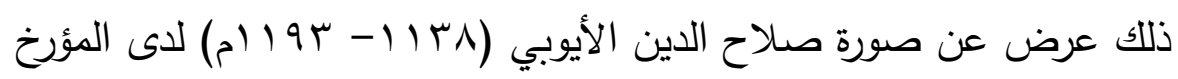

$$
\text { الفرنسي كلود كاهن (9.9 (19- 199 (19 ). }
$$




\section{الهوامش}

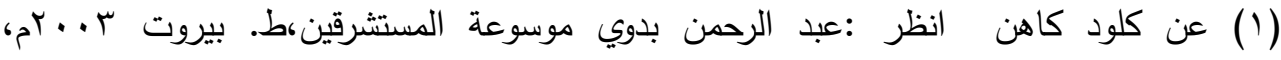

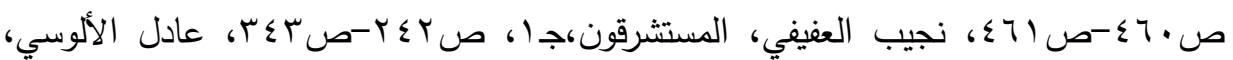

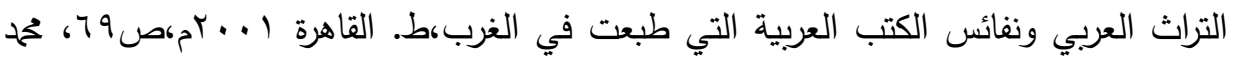

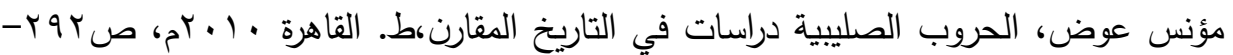
ص ص (ץ) عن ذلك انظر كلود كاهن :الثرق والغرب في زمن الحروب الصليبية،ت. أحمد الثيخ،ط.

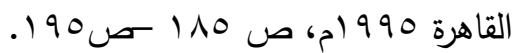

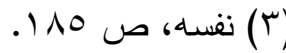

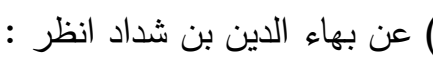

ابن شداد النوادر السلطانية والمحاسن اليوسفية، تحقيق جمال الدين الشيال،ط. القاهرة ع 97 ام، مقدمة

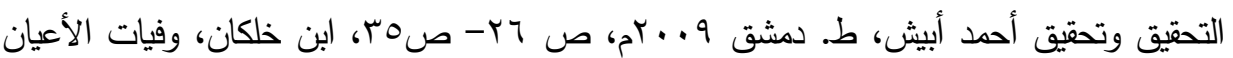

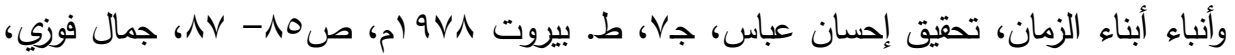

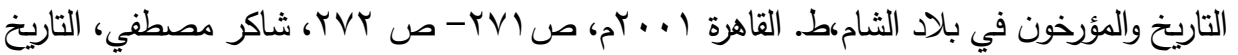
العربي والمؤرخون،جr،ط. بيروت .99 ام، صـ ||(1، نفسه، صلاح الدين الفارس المجاهد والملك

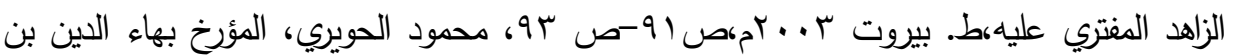

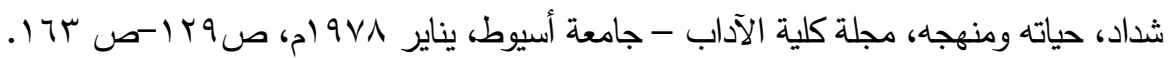

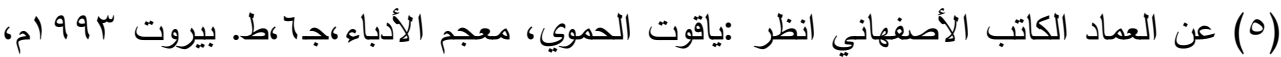

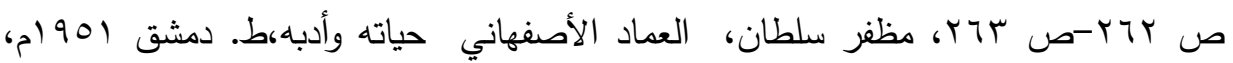

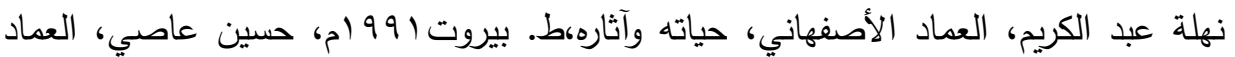

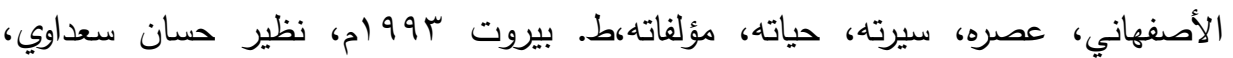

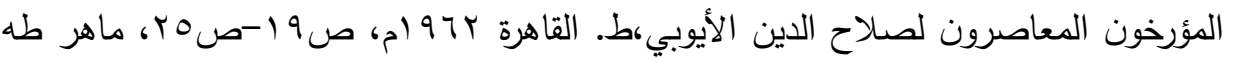

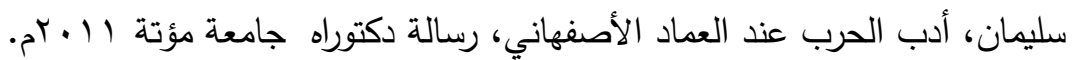

D. Richards, Emad al-Din al-Asfahani: Administrators Literature and historian "in Crusader and Muslims in Twelfth century Syria, ed Maya Shatmiller, Leiden.1993,PP.133-146.

$$
\text { : (ך) }
$$

William of Tyre, A History of Deeds done beyond The Sea, Trans.E.A. Babcock and A.C. Krey ,2 vols.,New York 1943. 
R.B.C. Huyens, un chapitre (XIX,12)de Son Historie retrouve, Latomos 21,1962,PP 811-829.

P. Edbury and J.B. Rowe, William of Tyre, Historian of Latin East, Cambridge 1988.

محم مؤنس عوض وهنادي السيد محمود، المؤرخ وليم الصوري بين رؤيتين عربية وغربية،ط.

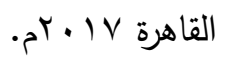

(العمل الدذكور يعد أول كتاب بالعربية عن مؤرخ الصليبين البارز).

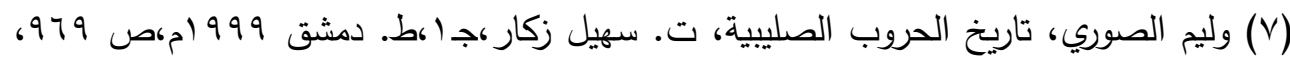

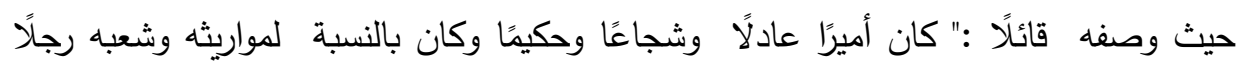

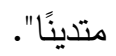
(^)

N. Elisseeff, Nur ad- Din un grand prince musulman au Temps des Croisades, 3 Vols., damas 1967.

(9) حققه سعيل زكار ، عن ذلك انظر :ابن شداد، كتاب الجهاد، تحقيق سهيل زكار، ضمن كتاب

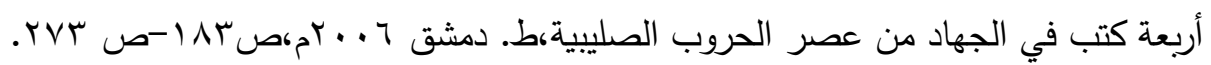
(· (1) عواد الأعظمي، تراث العرب الفكري والعلمي في فلسطين في ظل الحكم الإسلامي، المؤرخ

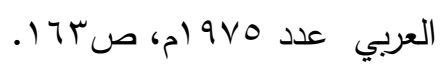

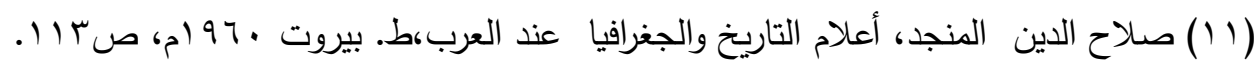

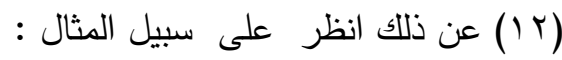
الواسطي المقدسي، فضائل البيت المقد، تحقيق إسحاق حسون، معهذ الدراسات الآسيوية

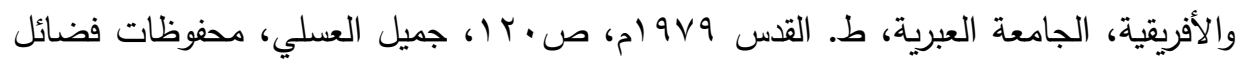

$$
\text { القدس،ط. عمان }
$$

(r ا ( ) عن ذلك انظر :الطرسوسي، تذكرة أرباب الألباب، تحقيق كلود كاهن، مجلة الدراسات الشرقية

$$
\text { B.E.O }
$$

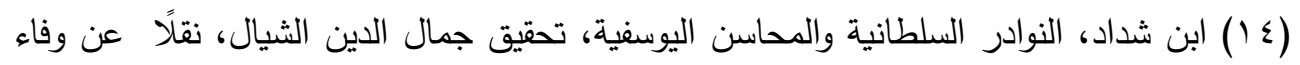

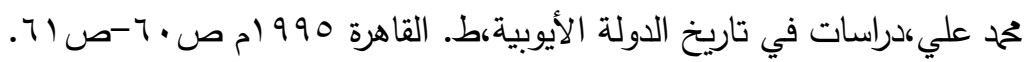

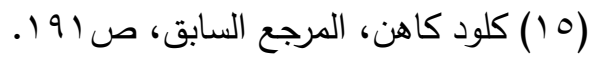

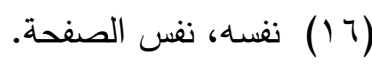

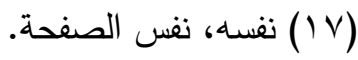

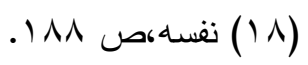

